\title{
Effect of galactooligosaccharide addition on the physical, optical, and sensory acceptance of vanilla ice cream
}

\author{
C. F. Balthazar, ${ }^{*}$ H. L. A. Silva, ${ }^{*}$ R. M. S. Celeguini, $†$ R. Santos, $†$ G. M. Pastore, $†$ C. A. Conte Junior, ${ }^{*}$ \\ M. Q. Freitas, ${ }^{*}$ L. C. Nogueira, $\ddagger$ M. C. Silva, $\ddagger$ and A. G. Cruz $\ddagger^{1}$ \\ ${ }^{*}$ Faculdade de Medicina Veterinária, Universidade Federal Fluminense (UFF), Rua Vital Brazil Filho, 64, Niterói, 24230340, Rio de Janeiro, Brazil \\ †Faculdade de Engenharia de Alimentos (FEA), Universidade Estadual de Campinas (UNICAMP), Caixa Postal 6121, 13083-862 Campinas-SP, \\ Brazil \\ łInstituto Federal de Educação, Ciência e Tecnologia do Rio de Janeiro (IFRJ), Mestrado Profissional em Ciência e Tecnologia de Alimentos \\ (PGCTA), Campus Rio de Janeiro, Rua Senador Furtado, 171, Maracanã, 20270-021, Rio de Janeiro, Brazil
}

\section{ABSTRACT}

The effect of the addition of galactooligosaccharide (GOS) on the physicochemical, optical, and sensory characteristics of ice cream was investigated. Vanilla ice cream was supplemented with $0,1.5$, and $3.0 \%$ (wt/wt) GOS and characterized for $\mathrm{pH}$, firmness, color, melting, overrun, as well as subjected to a discriminative sensory test (triangle test). For comparison purposes, ice creams containing fructooligosaccharide were also manufactured. The GOS ice creams were characterized by increased firmness and lower melting rates. Different perceptions were reported in the sensory evaluation for the $3.0 \%$ GOS ice cream when compared with the control, which was not observed for the fructooligosaccharide ice cream. Overall, the findings suggest it is possible to produce GOS ice cream with improved stability in relation to the physicochemical parameters and sensory perception.

Key words: galactooligosaccharide, ice cream, stability, sensory perception

\section{INTRODUCTION}

Prebiotics are nonviable food components that confer health benefits to the host associated with modulation of the intestinal flora (FAO, 2007). From a technological point of view, they induce significant changes on the organoleptic characteristics of food products, enhancing flavor and texture (Al-Sheraji et al., 2013).

Galactooligosaccharides (GOS) are produced by the transgalactosylation of lactose by the enzyme $\beta$-galactosidase, occurring in lactose-rich substrates, notably milk, milk whey, or a mixture of both (Kothari et al., 2014). They are stable to adverse $\mathrm{pH}$ and temperature conditions, resistant at $160^{\circ} \mathrm{C}$ for $10 \mathrm{~min}$

Received October 26, 2014

Accepted March 2, 2015.

${ }^{1}$ Corresponding author: food@globo.com at neutral $\mathrm{pH}$ or $120^{\circ} \mathrm{C}$ for the same period at $\mathrm{pH} 3$. At $\mathrm{pH} 2$, GOS is resistant at $100^{\circ} \mathrm{C}$ for up to $10 \mathrm{~min}$ (Sangwan et al., 2011). Their prebiotic effect is widely accepted, and several studies have reported the effect of their addition on the composition and activity of the intestinal flora (Krasaekoopt and Watcharapoka, 2014; Rattanaprasert et al., 2014; Bruno-Barcena. and Azcarate-Peril, 2015). However, no studies on the effect of GOS on food color were found in literature.

Ice creams and other refrigerated desserts are considered nutritive foods due to the presence of milk or fruits in their formulation, representing a source of proteins, vitamins, and minerals. As they are appreciated worldwide, regardless of culture, age, and socioeconomic level, the supplementation of ice creams with prebiotic ingredients or probiotic bacteria can add value to the product by providing functional appeal (Cruz et al., 2009). Several authors have already reported the functional potential of the ice cream matrix, and the addition of probiotic bacteria has been widely discussed (Alamprese et al., 2002, 2005; Fávaro-Trindade et al., 2007; Di Criscio et al., 2010), together with the sensory implications related to its addition (Soukoulis et al., 2010). The addition of other prebiotic ingredients, such as inulin and fructooligosaccharides, has also been investigated (Karaca et al., 2009). However, there is a lack of information on the effect of addition of GOS on the quality parameters of ice cream. Thus, the objective of the present study was to evaluate the effect of the addition of GOS on the physicochemical and optical properties and sensory acceptance of vanilla ice creams.

\section{MATERIALS AND METHODS}

\section{Prebiotic Ingredient}

The GOS mixture used in our study was produced by the activity of galactosyltransferases from Scopulariopsis sp. ATCC 44206, using lactose as substrate (Santos et al., 2009). The final product in the form 
of a dry powder that consisted of $28 \%$ (wt/wt) GOS with a degree of polymerization between 2 and 5, 50\% lactose, $15 \%$ glucose, and $7 \%$ galactose. In addition, for comparative purposes, an ice cream with $3.0 \mathrm{~g} / 100 \mathrm{~g}$ of fructooligosaccharide (FOS; Orafti, Tienen, Belgium) was produced, coded as F samples.

These prebiotics are traditionally used to enhance the sweetness level in food matrices. The percentage of prebiotics addition were based on the values established by the Brazilian legislation for these products, which recommends minimal concentration of $1.5 \mathrm{~g}$ per $100 \mathrm{~g}$ or $100 \mathrm{~mL}$ of product to provide the prebiotic effect (Brazil Ministry of Health, 2008).

\section{Ice Cream Processing}

Four ice creams were processed using a discontinuous domestic ice cream machine (Rival, São Paulo, SP, Brazil). The ice creams were supplemented with $0,1.5$, and $3.0 \mathrm{~g} / 100 \mathrm{~g}$ of GOS $(\mathbf{C}, \mathbf{1 . 5} \mathbf{G}$, and $\mathbf{3 G}$, respectively), proportional to the concentration of sucrose in the formulation. The amounts of the ingredients for each formulation are shown in Table 1 (Ferraz et al., 2012). Milk (Paulista, São Paulo, Brazil) was heated to $50^{\circ} \mathrm{C}$ and the glucose syrup (Doce Aroma, São Paulo, Brazil) was dissolved in warm milk. All the other ingredients were then added, including stabilizer (Duas Rodas, Jaraguá do Sul, Brazil), emulsifier (Lida, Diadema, Brazil), vanilla flavoring (Duas Rodas), milk powder (Itambé, Belo Horizonte, Brazil), vegetable fat (Vigor, São Caetano do Sul, Brazil), sucrose (Guarani, Olímpia, Brazil), and the prebiotics, according to Table 1. The ice cream mixtures were submitted to maturation at $5^{\circ} \mathrm{C}$ for $24 \mathrm{~h}$ before the air incorporation procedure (screw adjusted to $45 \%, 5$ min, $5^{\circ} \mathrm{C}$; Ferraz et al., 2012), packed into $100-\mathrm{mL}$ propylene packs, sealed by thermoinduction, and stored frozen at $-18^{\circ} \mathrm{C}$. All experiments were performed at laboratory scale, in triplicate, as well as the physicochemical and optical analyses. The consumer preference test was performed once.

\section{Physical and Optical Analyses}

The ice creams were characterized for physicochemical ( $\mathrm{pH}$, firmness, melting, overrun) and optical analysis (instrumental color) after $45 \mathrm{~d}$ of frozen storage. All analyses were carried out at least in triplicate. The $\mathrm{pH}$ was determined using a digital $\mathrm{pH}$ meter (Micronal, Piracicaba, Brazil), by direct insertion of the electrode into the sample. The ice creams were maintained at $20^{\circ} \mathrm{C}$ during the analyses.

The melting rates of the ice cream samples were analyzed at room temperature $\left(25 \pm 2^{\circ} \mathrm{C}\right)$. Fifty-gram samples were weighed and placed in suspended sieves at controlled ambient temperature. The volumes of ice cream were measured over $40 \mathrm{~min}$ and the melting rates were calculated from the linear portion of each melting curve (Ferraz et al., 2012).

Air incorporation (overrun) was determined by comparing the weight of the mixture before and after freezing, and calculated according to Equation 1 (Di Criscio et al., 2010):

$$
\begin{gathered}
\text { Overrun }(\%)=[\text { (weight of ice cream } \\
- \text { weight of liquid }) / \text { weight of liquid }] \times 100 \text {. }
\end{gathered}
$$

Firmness was evaluated using the TA-XT2i texture analyzer (Stable Micro Systems, Godalming, UK), calibrated with a $25-\mathrm{kg}$ load cell. The ice cream samples were maintained at $-18^{\circ} \mathrm{C}$ until the analysis. During testing, the samples were compressed by penetration of a 2-mm-diameter aluminum cylinder probe. The tests were carried out in the compression power mode with a pretest speed of $2.0 \mathrm{~mm} / \mathrm{s}$, and test and post-test speeds of $1 \mathrm{~mm} / \mathrm{s}$, with a penetration distance of 10.0 $\mathrm{mm}$. Three determinations were performed at approximately $-18^{\circ} \mathrm{C}$ for each batch.

Color Quest II Hunterlab spectrophotometer (Reston, VA) was used for color determination according to the CIELCh system. In the $L^{*} C^{*} h_{a b}$ system, chroma $\left(C^{*}\right)$ and hue angle $\left(h_{a b}\right)$ were calculated from equations 2 and 3 (Vargas et al., 2008), respectively. The values for light and dark are represented by $L$ (luminosity), red by $+a$, green by $-a$, yellow by $+b$, and blue by $-b$ in a Cartesian plane. Similar procedures were performed by Corradini et al. (2014):

$$
\begin{gathered}
C^{*}=\left[\left(a^{*}\right)^{2}+\left(b^{*}\right)^{2}\right]^{1 / 2} ; \\
h_{a b}=\tan ^{-1}\left[b^{*} / a^{*}\right] .
\end{gathered}
$$

Table 1. Ice cream formulation ${ }^{1}$

\begin{tabular}{lrrrr}
\hline Ingredients (g) & $\mathrm{C}$ & \multicolumn{1}{c}{$3 \mathrm{~F}$} & $1.5 \mathrm{G}$ & \multicolumn{1}{c}{$3 \mathrm{G}$} \\
\hline Milk & 500.0 & 500.0 & 500.0 & 500.0 \\
Milk powder & 35.0 & 35.0 & 35.0 & 35.0 \\
Sucrose & 150.0 & 147.0 & 148.5 & 147.0 \\
Glucose syrup & 25.0 & 25.0 & 25.0 & 25.0 \\
Vegetable fat & 15.0 & 15.0 & 15.0 & 15.0 \\
Vanilla & 10.0 & 10.0 & 10.0 & 10.0 \\
Stabilizer & 1.5 & 1.5 & 1.5 & 1.5 \\
Emulsifier & 1.0 & 1.0 & 1.0 & 1.0 \\
Fructooligosaccharide (F) & - & 3.0 & - & - \\
Galactooligosaccharide (G) & - & - & 1.5 & 3.0 \\
Total & 737.5 & 737.5 & 737.5 & 737.5 \\
\hline${ }^{1} \mathrm{C}=0$ g/100 g of galactooligosaccharides (GOS); 3F $=3.0 \mathrm{~g} / 100 \mathrm{~g}$ of \\
fructooligosaccharides; 1.5G = 1.5 g/100 g of GOS; 3G = 3.0 g/100 g \\
of GOS; the same formulation was used for the following experimental \\
ice cream: F, 1.5G, and 3G, except for sucrose content, which decreas- \\
es proportionally, as 3, 1.5, and 3 g/100g respectively.
\end{tabular}


Table 2. Physical analysis of ice creams added with fructooligosaccharide and galactooligosaccharide ${ }^{1}$

\begin{tabular}{lcrrr}
\hline Physical analysis & $\mathrm{C}$ & $\mathrm{F}$ & \multicolumn{1}{c}{$1.5 \mathrm{G}$} & \multicolumn{1}{c}{$3.0 \mathrm{G}$} \\
\hline $\mathrm{pH}$ & $7.51^{\mathrm{b}}$ & $7.51^{\mathrm{a}}$ & $7.56^{\mathrm{a}}$ & $7.52^{\mathrm{a}}$ \\
Firmness (N) & $9.50^{\mathrm{c}}$ & $2069.66^{\mathrm{a}}$ & $830.81^{\mathrm{b}}$ & $2492.17^{\mathrm{a}}$ \\
Melting rate (mL/min) & $2.52^{\mathrm{a}}$ & $2.86^{\mathrm{a}}$ & $1.15^{\mathrm{c}}$ & $2.31^{\mathrm{b}}$ \\
Overrun (\%) & $42.3^{\mathrm{d}}$ & $49.8^{\mathrm{c}}$ & $55.7^{\mathrm{a}}$ & $64.6^{\mathrm{b}}$ \\
\hline
\end{tabular}

${ }^{a-d}$ Mean values in the same row with different letters differ $(P<0.05)$.

${ }^{1} \mathrm{C}=0 \mathrm{~g} / 100 \mathrm{~g}$ of galactooligosaccharides (GOS); $\mathrm{F}=3.0 \mathrm{~g} / 100 \mathrm{~g}$ of fructooligosaccharides; $1.5 \mathrm{G}=1.5 \mathrm{~g} / 100 \mathrm{~g}$ of GOS; $3 \mathrm{G}=3.0 \mathrm{~g} / 100$ $\mathrm{g}$ of GOS.

Readings were carried out in quadruplicate using illuminant $\mathrm{D}^{65}$, visual angle of $10^{\circ}$, and reflectance calibration mode with specular excluded.

\section{Consumer Test}

A series of discrimination tests, triangular tests, was carried out to evaluate consumer perception with respect to the addition of prebiotics to the vanilla ice cream. The samples were served at $-18^{\circ} \mathrm{C}$, in random order, in plastic cups identified with a random 3 -digit code. The panelists were instructed to rinse their mouths with water between samples. The different attributes perceived by consumers were written in an open comment box (Varela et al., 2014). Four triangular tests were carried out at the same day, in the following sequence: (1) 2 control samples and 1 sample supplemented with $1.5 \mathrm{G}$; (2) 2 control samples and 1 sample supplemented with 3G; (3) 2 F samples and 1 sample supplemented with 1.5G; and (4) $2 \mathrm{~F}$ samples and 1 sample supplemented with $3 \mathrm{G}$.

The following protocol was then performed. Panelists were asked to select the odd sample in the 3-sample set. Seventy ice cream consumers (60\% women, $40 \%$ men, aged 18-54) were recruited at random from the University of Campinas to take part in the consumer test, and the selection criterion was the nonexistence of allergic reactions to milk (Drake, 2007). Consumers were invited to report the sensory attribute that differentiated the samples (appearance, aroma, flavor, or texture). Samples were presented in a monadic way, and consumers were instructed to rinse their mouths out with distilled water between tests to avoid cold carry-over effects. All the sensory analyses were carried out in individual booths with controlled temperature and humidity in the Sensory Analysis Laboratory of the Department of Food Technology, University of Campinas.

This different approach was performed according to the new context of the sensory and consumer science, where consumers are able to describe and relate the perceptions about the sensory descriptors of food prod- ucts (Varela and Ares, 2012; Jervis and Drake, 2014). With respect to dairy foods, these studies have been performed in cheese pies (Marcano et al., 2015), functional yogurts (Cruz et al., 2013a; Cadena et al., 2014), and cheeses (Hanaei et al., 2015). In this sense, the present study aimed to check by the discrimination test whether the consumers are able to perceive the overall difference among the products (Drake, 2007).

\section{Statistical Analyses}

As a first step, all variables were subjected to Hartley's test to check for homogeneity of variance within the treatments, and one-way ANOVA was applied to the physicochemical and optical analysis to identify contrasts among the ice cream samples. Principal component analysis (Cruz et al., 2013b; Matera et al., 2014; Gaze et al., 2015a) was performed by Pearson correlation using the mean values of the physicochemical results and color measurements The matrix data set was composed of 4 lines and 7 columns, with the former the samples and the latter the results of the different analyses. Data were autoscaled before analysis. The statistical package was XLSTAT software version 2013.5 (Addinsoft, Paris, France). The results of the triangular tests were analyzed using the corresponding table for repeated triangle tests following a unilateral hypothesis, considering $5 \%$ of significance, as recently reported by Varela et al. (2014).

\section{RESULTS AND DISCUSSION}

\section{Physicochemical and Optical Analyses}

Table 2 shows the results for the physicochemical characteristics of the ice creams. Overall, the supplementation of ice creams with prebiotic ingredients affected all parameters $(P<0.05)$, except for $\mathrm{pH}$ where no significant difference was observed $(P>0.05)$. Regardless of the addition of prebiotics, high $\mathrm{pH}$ values were observed (7.51-7.56); this was probably due to the chemical structure of the compounds added, as all prebiotics were carbohydrates, which could influence this parameter.

With respect to the attribute firmness, the control sample was less hard, differing from the ice creams supplemented with prebiotics $(P<0.05)$. The addition of GOS resulted in an increase in firmness of approximately $87 \%$ for $1.5 \mathrm{G}$ and $3 \mathrm{G}$ ice creams. No significant differences were observed between $3.0 \mathrm{G}$ and $\mathrm{F}$ samples $(P>0.05)$, but both differed from the sample containing only sugar and from the $1.5 \mathrm{G}$ samples. The addition of the prebiotics GOS and FOS caused an effect on the firmness of the ice creams, which increased with 
increasing oligosaccharides concentration. This is related to the chemical nature of the prebiotics, which are carbohydrates showing an affinity for the serum phase of the ice cream, increasing viscosity and thus reflecting on product firmness. Similar results were reported for ice creams supplemented with inulin (Di Criscio et al., 2010).

The addition of prebiotics resulted in a decrease in the melting rate of the ice creams $(P<0.05)$, leading to greater product stability. In particular, the addition of 1.5 and $3.0 \%$ GOS provided the lowest values of 1.15 and $2.31 \mathrm{~L} / \mathrm{min}$, respectively, which are directly related to the GOS concentration. Indeed, during storage of ice cream, an increase of 30 to $40 \%$ of ice crystals was observed as compared with the product matrix, which may be due to recrystallization of ice during temperature fluctuations (Muse and Hartel, 2004). The addition of prebiotics such as GOS can be a potential alternative to control this phenomenon, acting as stabilizing agents by increasing the viscosity of the serum phase and hence limiting water diffusion. In addition, as a prebiotic ingredient, GOS can minimize the occurrence of iciness, a defect that manifests itself during storage of ice creams, resulting in defective texture and an excessively cold product, due to the formation of ice. Although our findings suggest that the addition of GOS had a positive effect on the ice cream stability, FOS exhibited superior performance. Similar results were found for the supplementation of ice cream with other prebiotics, namely oligofructose and inulin (Akalin and Erişir, 2008; Di Criscio et al., 2010). It is well established that prebiotics may also facilitate air incorporation and foam stabilization by increasing the viscosity of the aqueous phase (by increasing solute concentration or gelation) surrounding the air cell interface, raising the physical barrier against air cell destabilization (Soukoulis et al., 2014).

The current results also showed that the addition of prebiotics caused an increase in overrun of the ice creams $(P<0.05)$, with a positive contribution to air incorporation. In particular, the addition of 1.5 and $3.0 \mathrm{~g} / 100 \mathrm{~g}$ of GOS provided the highest overrun rates of 55.7 and $64.6 \%$, respectively, as a function of the concentration added. Air incorporation is a compulsory step in the manufacture of ice creams, as it influences the sensory quality by providing a softer texture to the product, and its stability is dependent on the ingredients and procedures used in the manufacturing process and storage conditions. Larger air cells resulting from higher overrun lead to greater viscosity and firmness values, and hence to a greater fat destabilization, decreasing melting rate. In addition, air is a poor conductor of heat energy and has a negative effect on heat transfer in ice creams with greater overrun (Sofjan and
Hartel, 2004). The present study demonstrated that the addition of prebiotics, especially GOS, resulted in ice creams with greater overrun, which could contribute to a more stable product. Prasad et al. (2013) reported that the addition of GOS in yogurt also produced similar effects, including lower syneresis and improved firmness, with global effect at the intrinsic quality parameters.

Table 3 shows the results of instrumental color for the parameters $L^{*}, C^{*}$, and $h$ of the ice cream samples containing different oligosaccharides concentrations. The luminosity tended to increase, with no significant difference for the control sample as compared with the other formulations $(P<0.05)$. Despite the fact the samples containing GOS did not differ statistically from each other, they were statistically different from the sample containing FOS. With respect to saturation $\left(C^{*}\right)$, significant differences were observed for the control sample when compared with the samples containing FOS and GOS, and samples with $1.5 \mathrm{~g} / 100 \mathrm{~g}$ of GOS were different from the others. The hue angle $(h)$ of the samples varied from 74.63 to $77.92^{\circ}$ and significant differences were observed for all samples, although they were all located in the yellow quadrant, as expected, for vanillaflavored ice creams. The addition of GOS resulted in a slight alteration in the luminosity of the ice creams when compared with the control sample, as evidenced by the lower $L$ values (77.93 and 77.92, respectively). The $\mathrm{F}$ and $\mathrm{C}$ samples were lighter, as they presented the higher $L$ values (79.15 and 78.40, respectively). Indeed, $L$ is an approximate measurement of luminosity, which is the property according to which each color can be considered as equivalent to a member of the gray scale, between black and white within the range 0 to 100 (Pathare et al., 2013). Conversely, the samples containing GOS presented higher $C^{*}$ values (33.53 and 30.06 , respectively), suggesting that they are perceived more intensely by consumers; this is because the higher the chroma values, the higher the color intensity of the sample (Pathare et al., 2013). However, as reported in the sensory evaluation, this change did not have effect on consumer perception of the samples.

\section{Consumer Test}

The results of the triangular test indicated that the $1.5 \mathrm{G}$ and $3 \mathrm{G}$ ice creams were perceived differently $(P$ $<0.05)$ from the $\mathrm{C}$ ice cream by 52 and 49 consumers, respectively. The opposite was observed when these ice creams were compared with the $\mathrm{F}$ samples, once $3 \mathrm{G}$ ice creams were similar to $\mathrm{F}$ ice creams. Indeed, when comparing the ice cream samples with the $\mathrm{C}$ sample, 51 consumers observed differences between the samples, whereas only 25 consumers found differences when the 
Table 3. Optical analysis of ice creams added with fructooligosaccharide and galactooligosaccharide ${ }^{1}$

\begin{tabular}{lcccc}
\hline $\begin{array}{l}\text { Color } \\
\text { parameter }\end{array}$ & $\mathrm{C}$ & $\mathrm{F}$ & $1.5 \mathrm{G}$ & $3.0 \mathrm{G}$ \\
\hline$L$ & $78.40^{\mathrm{ab}}$ & $79.15^{\mathrm{a}}$ & $77.93^{\mathrm{b}}$ & $77.92^{\mathrm{b}}$ \\
$C^{*}$ & $28.30^{\mathrm{bc}}$ & $28.15^{\mathrm{c}}$ & $33.53^{\mathrm{a}}$ & $30.06^{\mathrm{b}}$ \\
$h$ & $77.92^{\mathrm{a}}$ & $75.97^{\mathrm{b}}$ & $74.63^{\mathrm{d}}$ & $75.65^{\mathrm{c}}$ \\
\hline
\end{tabular}

${ }_{\mathrm{a}-\mathrm{d}}$ Mean values in the same row with different letters differ $(P<0.05)$. ${ }^{1} \mathrm{C}=0 \mathrm{~g} / 100 \mathrm{~g}$ of galactooligosaccharides (GOS); $\mathrm{F}=3.0 \mathrm{~g} / 100 \mathrm{~g}$ of fructooligosaccharides; $1.5 \mathrm{G}=1.5 \mathrm{~g} / 100 \mathrm{~g}$ of GOS; $3 \mathrm{G}=3.0 \mathrm{~g} / 100$ $\mathrm{g}$ of GOS.

ice creams were compared with the F samples (tabulated value to have minimal statistical significance, 43 ; $P<0.05)$. The attribute texture received the greatest number of citations (80\%) and could be considered responsible for the difference between $3 \mathrm{G}$ ice creams, followed by flavor (30\%) and aroma (20\%). It could also be related to greater firmness of the $3 \mathrm{G}$ samples and lower sweetness level due to the partial substitution of sugar by GOS. In fact, consumers appreciate the sweet flavor provided by sucrose addition; thus, greater changes in the formulation of ice creams may be related to the addition of sweeteners. The consumers' answers in the discrimination test confirm the results of the current study, which can be used for other products.

As a starting point, prebiotic food products and similar conventional products (Cruz et al., 2010) should have equivalent consumer acceptance as well as sensory properties. In this sense, studies have shown that supplementation with prebiotics may affect the sensory acceptance of dairy products (Cruz et al., 2013c; Pimentel et al., 2013). In particular, texture is an important sensory attribute in the development of prebiotic

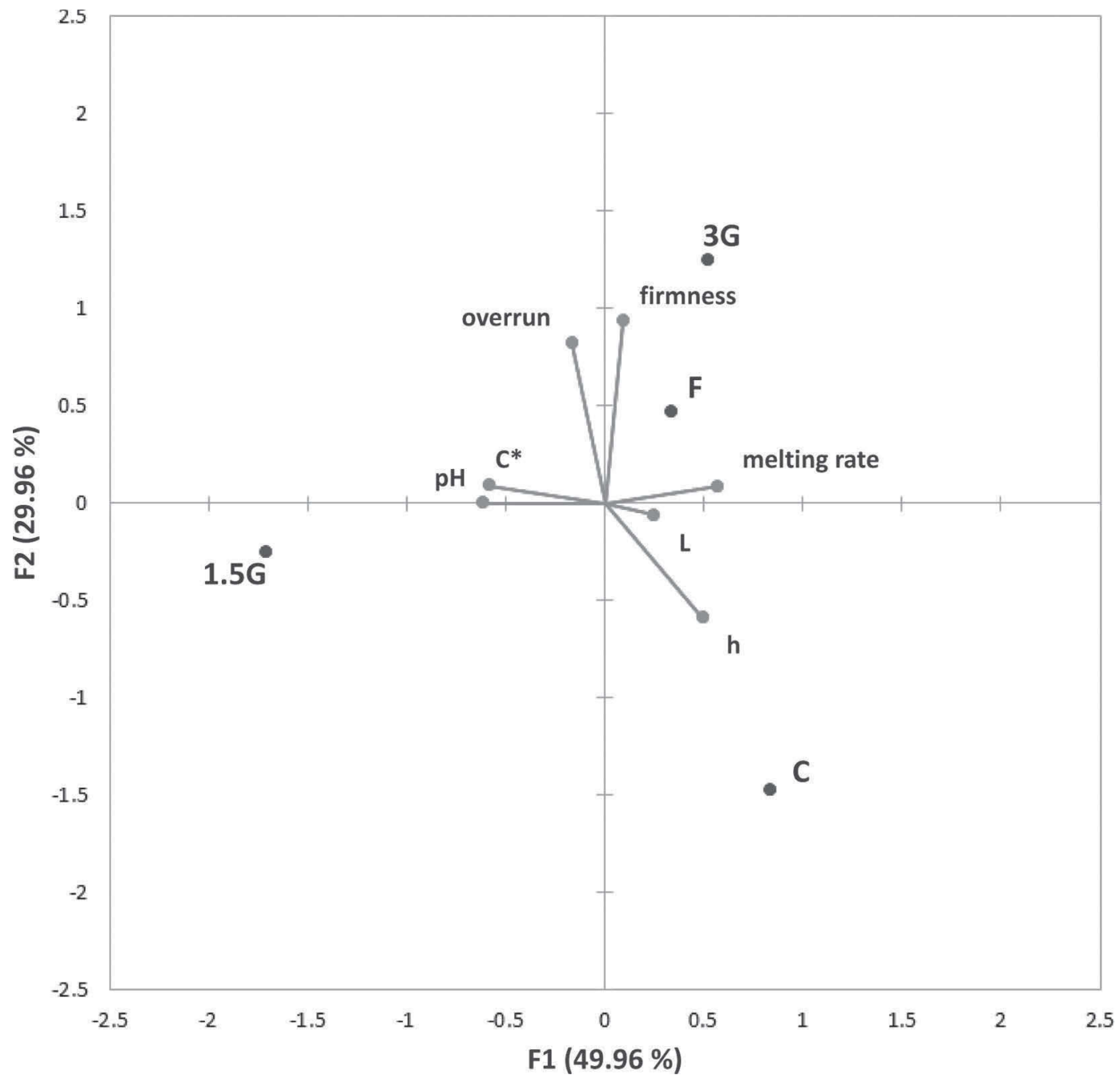

Figure 1. Principal component analysis $(\mathrm{PCA})$ of prebiotic ice cream samples. $\mathrm{C}=0 \mathrm{~g} / 100 \mathrm{~g}$ of galactooligosaccharides $(\mathrm{GOS}) ; \mathrm{F}=3.0$ $\mathrm{g} / 100 \mathrm{~g}$ of fructooligosaccharides; $1.5 \mathrm{G}=1.5 \mathrm{~g} / 100 \mathrm{~g}$ of $\mathrm{GOS} ; 3 \mathrm{G}=3.0 \mathrm{~g} / 100 \mathrm{~g}$ of GOS; $\mathrm{C}^{*}=$ chroma. 
dairy foods, because it is perceived in a different way by consumers (Jervis et al., 2014).

To the best of our knowledge, no study exists on the development of ice cream formulations containing GOS. In this sense, our findings highlight the possibility to produce ice creams supplemented with $1.5 \%$ (wt/wt) GOS, with lower sweetness intensity and differentiated functional attributes, with health benefits provided by the prebiotic ingredient. Further studies should cover a hedonic test using a representative sample of consumers (Morais et al., 2014a; Gaze et al., 2015b), as well as the development of sensory profiling (Pimentel et al., 2013; Morais et al., 2014b). On the other hand, clinical studies using food matrices supplemented with GOS are also welcome (Lollo et al., 2015; Morato et al., 2015).

The principal component analysis performed with the data of physicochemical and optical analyses of the ice cream samples is shown in Figure 1. Two main components (F1-F2) were used, which accounted for $79.92 \%$ of data with a range of 49.96 and $29.96 \%$ for the first and second component, respectively. The high variability obtained suggests that the physicochemical and optical analysis provided relevant information and summarized the problematic of the addition of prebiotics in ice cream formulations. The samples $3 \mathrm{G}$ and $\mathrm{F}$ are associated with firmness and melting rate, whereas the $1.5 \mathrm{G}$ ice cream is associated with $C^{*}$ index and $\mathrm{pH}$. Finally, the $\mathrm{C}$ ice cream was associated with the color parameters $L$ and $h$; F1 was positively associated with $\mathrm{pH}$, melting rate, and $C^{*}$, whereas $\mathrm{F} 2$ was associated with firmness, overrun, and $h$. These findings summarize the main parameters affected by the addition of the prebiotic ingredient in the ice cream formulations.

\section{CONCLUSIONS}

The present results suggest that the addition of prebiotics such as GOS may have a positive effect on physicochemical, optical, and sensory characteristics of vanilla ice cream. In general, an increase in firmness and a decrease in melting rate of the ice creams was observed, which contributed to a greater stability of the product. In addition, an increase in overrun was observed for the ice creams supplemented with GOS. From the sensory point of view, although the ice creams supplemented with $3.0 \%$ (wt/wt) GOS stood out for the attributes sweetness flavor and texture, they were not different when compared with the $\mathrm{F}$ ice cream, which contains a recognized prebiotic used in ice cream formulation. Our findings are relevant for the functional dairy industry, as we demonstrated the effects of using different prebiotics in dairy foods, in particular GOS, which has not been widely explored. Therefore, it is possible to develop vanilla ice creams supplemented with GOS.

\section{REFERENCES}

Akalin, A. S., and D. Erișir. 2008. Effects of inulin and oligofructose on the rheological characteristics and probiotic culture survival in low-fat probiotic ice cream. J. Food Sci. 73:M184-188.

Al-Sheraji, S. H., A. Ismail, M. Y. Manap, S. Mustafa, R. M. Yusof, and F. A. Hassan. 2013. Prebiotics as functional foods: A review. J. Funct. Foods 5:1542-1553.

Alamprese, C., R. Foschino, M. Rossi, C. Pompei, and S. Corti. 2005. Effects of Lactobacillus rhamnosus CG addition in ice cream. Int. J. Dairy Technol. 58:200-206.

Alamprese, C., R. Foschino, M. Rossi, C. Pompei, and L. Savani. 2002. Survival of Lactobacillus johnsonii La1 and the influence of its addition in retail-manufactured ice cream produced with different sugar and fat concentration. Int. Dairy J. 12:201-208.

Brazil Ministry of Health. 2008. Resolução RDC n.2 aprova o regulamento técnico de substâncias bioativas e probióticos isolados com alegação de propriedade funcional e ou de saúde. National Agency for Sanitary Vigilance, Ministry of Health, Brasília, DF, Brazil.

Bruno-Barcena, J. M., and M. A. Azcarate-Peril. 2015. Galacto-oligosaccharides and colorectal cancer: Feeding our intestinal probiome. J. Funct. Foods 12:92-108.

Cadena, R. S., D. Caimi, I. Jaunarena, I. Lorenzo, L. Vidal, G. Ares, R. Deliza, and A. Giménez. 2014. Comparison of rapid sensory characterization methodologies for the development of functional yogurts. Food Res. Int. 64:445-455.

Corradini, S. A., S. G. S. Madrona, J. V. Visentainer, E. G. Bonafe, C. B. Carvalho, P. M. Roche, and I. N. Prado. 2014. Sensorial and fatty acid profile of ice cream manufactured with milk of crossbred cows fed palm oil and coconut fat. J. Dairy Sci. 97:6745-6753.

Cruz, A. G., A. E. C. Antunes, A. L. O. P. Sousa, J. A. F. Faria, and S. M. I. Saad. 2009. Ice cream as a probiotic food carrier. Food Res. Int. 42:1-7.

Cruz, A. G., R. S. Cadena, M. B. V. B. Alvaro, A. S. Sant'Ana, C. A. F. Oliveira, J. A. F. Faria, H. M. A. Bolini, and M. M. C. Ferreira. 2013b. Assessing the use of different chemometric techniques to discriminate low-fat and full-fat yogurts. Lebenson. Wiss. Technol. 50:210-214.

Cruz, A. G., R. S. Cadena, W. F. Castro, E. A. Esmerino, J. B. Rodrigues, L. V. Gaze, J. A. F. Faria, M. Q. Freitas, R. Deliza, and H. M. A. Bolini. 2013a. Consumer perception of probiotic yogurt: Performance of check all that apply (CATA), projective mapping, sorting and intensity scale. Food Res. Int. 42:601-610.

Cruz, A. G., R. S. Cadena, E. H. M. Walter, A. M. Mortazavian, D. Granato, J. A. F. Faria, and H. M. A. Bolini. 2010. Sensory analysis: Relevance for prebiotic, probiotic, and synbiotic product development. Comp. Rev. Food Sci. Food Saf. 9:358-373.

Cruz, A. G., R. N. Cavalcanti, L. M. R. Guerreiro, A. S. Sant'Ana, L. C. Nogueira, C. A. F. Oliveira, R. L. Cunha, J. A. F. Faria, and H. M. A. Bolini. 2013c. Developing a prebiotic yogurt: Rheological, physico-chemical and microbiological aspects and adequacy of survival analysis methodology. J. Food Eng. 114:323-330.

Di Criscio, T., A. Fratianni, R. Mignogna, L. Cinquanta, R. Coppola, E. Sorrentino, and G. Panfili. 2010. Production of functional probiotic, prebiotic, and synbiotic ice creams. J. Dairy Sci. 93:45554564 .

Drake, M. A. 2007. Invited review: Sensory analysis of dairy foods. J. Dairy Sci. 90:4925-4937.

FAO. 2007. Technical Meeting on Prebiotics. Food and Agriculture Organization of United Nations, Rome, Italy.

Fávaro-Trindade, C. S., J.C.C. Balieiro, P.F. Dias, F.A. Sanino, and C. Boschini. 2007. Effects of culture, $\mathrm{pH}$ and fat concentration on melting rate and sensory characteristics of probiotic fermented yellow mombin (Spondias mombin) ice creams. Food Sci. Technol. Int. 53:285-291. 
Ferraz, J. L., A. G. Cruz, R. S. Cadena, M. Q. Freitas, U. M. Pinto, C. C. Carvalho, J. A. F. Faria, and H. M. A. Bolini. 2012. Sensory acceptance and survival of probiotic bacteria in ice cream produced with different overrun levels. J. Food Sci. 77:S24-S28.

Gaze, L. V., M. P. Costa, M. L. G. Monteiroa, J. A. A. Lavoratoc, C. A. Conte Júniora, R. S. L. Raicesb, A. G. Cruz, and M. Q. Freitas. 2015a. Dulce de Leche, a typical product of Latin America: Characterization by physicochemical, optical and instrumental methods. Food Chem. 169:471-477.

Gaze, L. V., B. R. Oliveira, L. L. Ferrao, D. Granato, R. N. Cavalcanti, C. A. Conte Júnior, A. G. Cruz, and M. Q. Freitas. 2015b. Preference mapping of dulce de leche commercialized in Brazilian markets. J. Dairy Sci. 98:1443-1454.

Hanaei, F., G. Cuvelier, and J. M. Sieffermann. 2015. Consumer texture descriptions of a set of processed cheese. Food Qual. Prefer. 40:316-325.

Jervis, S. M., and M. Drake. 2014. The use of qualitative research methods in quantitative science: A review. J. Sens. Stud. 29:234247.

Jervis, S. M., P. Gerard, S. Drake, K. Lopetcharat, and M. Drake. 2014. The perception of creaminess in sour cream. J. Sens. Stud. $29: 248-257$.

Karaca, O. B., M. Güven, K. Yasar, S. Kaya, and T. Kahyaoglu. 2009. The functional, rheological and sensory characteristics of ice creams with various fat replacers. Int. J. Dairy Technol. 62:93-99.

Kothari, D., S. Patel, and A. Goyal. 2014. Therapeutic spectrum of nondigestible oligosaccharides: overview of current state and prospect. J. Food Sci. 79:R1491-1498.

Krasaekoopt, W., and S. Watcharapoka. 2014. Effect of addition of inulin and galactooligosaccharide on the survival of microencapsulated probiotics in alginate beads coated with chitosan in simulated digestive system, yogurt and fruit juice. Lebenson Wiss. Technol. 57:761-766

Lollo, P. C. B., P. M. Morato, C. S. Moura, M. M. Oliveira, A. G. Cruz, J. A. F. Faria, J. Amaya-Farfan, and M. Cristianini. 2015. Ultra-high temperature plus dynamic high pressure processing: An effective combination for potential probiotic fermented milk processing which attenuate exercise-induced immune suppression in Wistar rats. J. Funct. Foods 14:141-148.

Marcano, J., G. Ares, and S. Fiszman. 2015. Comparison of partial and global projective mapping with consumers: A case study with satiating cheese pies. Food Res. Int. 67:323-330.

Matera, J. A., A. G. Cruz, R. S. L. Raices, M. C. Silva, L. C. Nogueira, R. N. Cavalcanti, M. Q. Freitas, and C. A. Conte Junior. 2014. Discrimination of Brazilian artisanal and inspected pork sausages: Application of unsupervised, linear and non-linear supervised chemometric methods. Food Res. Int. 64:380-386.

Morais, E. C., A. G. Cruz, J. A. F. Faria, and H. M. A. Bolini. 2014a. Prebiotic gluten-free bread: Sensory profiling and drivers of liking. Lebenson. Wiss. Technol. 55:248-254.

Morais, E. C., A. R. Morais, A. G. Cruz, and H. M. A. Bolini. 2014b. Development of chocolate dairy dessert with addition of prebiotics and replacement of sucrose with different high-intensity sweeteners. J. Dairy Sci. 97:2600-2609.

Morato, P. N., J. B. Rodrigues, C. S. Moura, F. G. Drummond e Silva, E. A. Esmerino, A. G. Cruz, H. M. A. Bolini, J. Amaya-Farfan, and P. C. B. Lollo. 2015. Omega-3 enriched chocolate milk: A functional drink to improve health during exhaustive exercise. J. Funct. Foods 14:676-683.

Muse, M. R., and R. W. Hartel. 2004. Ice cream structural elements that affect melting rate and hardness. J. Dairy Sci. 87:1-10.

Pimentel, T. C., A.G. Cruz, and S.H. Prudencio. 2013. Short communication: Influence of long-chain inulin and Lactobacillus paracasei subspecies paracase $i$ on the sensory profile and acceptance of a traditional yogurt. J. Dairy Sci. 96:6233-6241.

Prasad, L. N., F. Sherkat, and N. P. Shah. 2013. Influence of galactooligosaccharides and modified waxy maize starch on some attributes of yogurt. J. Food Sci. 78:M77-M83.

Rattanaprasert, M., S. Roos, R. W. Hutkins, and J. Walter. 2014. Quantitative evaluation of synbiotic strategies to improve persistence and metabolic activity of Lactobacillus reuteri DSM 17938 in the human gastrointestinal tract. J. Funct. Foods 10:85-94.

Pathare, P. B., U. L. Opara, and F. Al-J. Al Said. 2013. Colour measurement and analysis in fresh and processed foods: A review. Food Bioprocess. Technol. 6:36-60.

Sangwan, V., S. K. Tomar, R. R. B. Singh, A. K. Singh, and B. Ali. 2011. Galactooligosaccharides: Novel components of designer foods. J. Food Sci. 76:R103-R111.

Santos, R., A. P. R. Simiqueli, and G. M. Pastore. 2009. Production of galactooligosaccharide by Scopulariopis sp. Cienc. Tecnol. Alim. 29:682-689.

Sofjan, R. P., and R. W. Hartel. 2004. Effects of overrun on structural and physical characteristics of ice cream. Int. Dairy J. 14:255-262.

Soukoulis, C., I. D. Fisk, and T. Bohn. 2014. Ice cream as a vehicle for incorporating health-promoting ingredients: Conceptualization and overview of quality and storage stability. Comp. Rev. Food Sci. Food Saf. 13:627-655.

Soukoulis, C., E. Lyroni, and C. Tzia. 2010. Sensory profiling and hedonic judgement of probiotic ice cream as a function of hydrocolloids, yogurt and milk fat content. Lebenson. Wiss. Technol. 43:1351-1358

Varela, P., and G. Ares. 2012. Sensory profiling, the blurred line between sensory and consumer science. A review of novel methods for product characterization. Food Res. Int. 48:893-908.

Varela, P., A. Tárrega, A. Salvador, A. Leal, J. Flanagan, M. Roller, N. Feuillere, N. Issaly, and S. Fiszman. 2014. Diabetic and nondiabetic consumers' perception of an apple juice beverage supplemented with a Fraxinus excelsior L. seed extract having potential glucose homeostasis benefits. Lebenson. Wiss. Technol. 57:648655 .

Vargas, M., M. Cháfer, A. Albors, A. Chiralt, and C. González-Martínez. 2008. Physicochemical and sensory characteristics of yoghurt produced from mixtures of cows' and milk. Int. Dairy J. 18:1146-1152. 